\title{
Assessment of new conditions for oil extraction from shark liver pool
}

\begin{abstract}
The objective of the work is to perform the partial chemical characterization of the liver oil pool of shark species Ginglimostoma cirratun, Carcharhinus longimanus, and Carcharhinus falciformis captured in the north central coast of Cuba and extracted at $50^{\circ}$ $\mathrm{C}$ for $20 \mathrm{~min}$. Parameters are determined such as the acid value, refractive value, relative density, saponification value, content of insoluble impurities in n-hexane, anisidina value, peroxide value and the UV-Vis spectrum, where it is shown that the oil is suitable for consumption provided that the sampling is carried out inside the liver sample. Shown that the oil extracted under these conditions meets the quality parameters required for its use.
\end{abstract}

Keywords: Shark liver oil, method of extraction, chemical properties
Volume 4 Issue I - 2020

Pedro César Quero-Jiménez, ${ }^{1,2}$ Lester Alejandro Arias Felipe, ${ }^{2,4}$ Darlene Lugo Ramírez, ${ }^{3}$ Julio Omar Prieto García, ${ }^{3}$ María Elisa Jorge Rodríguez, ${ }^{4}$ Jorge de la Torre, ${ }^{3}$ Osvaldo Norman Montenegro, ${ }^{2}$ Dulce María González, ${ }^{4}$ Luis Moya Jiménez, ${ }^{2}$ Reinaldo Molina Ruíz $z^{2}$

Institute of Catalysis and Petrochemical Research, National University of the Littoral, Argentina

2Chemical Bioactive Center, University "Marta Abreu” of Las Villas, Cuba

${ }^{3}$ Department of Chemistry Degree, University “Marta Abreu” of Las Villas, Cuba

${ }^{4}$ Department of Pharmacy Degree, University “Marta Abreu” of Las Villas, Cuba

Correspondence: Pedro César Quero-Jiménez, Institute of Catalysis and Petrochemical Research, National University of the Littoral, Santa Fe, Argentina,

Email pquero.jimenez@gmail.com

Received: December 23, 2019 | Published: February 27, 2020

\section{Introduction}

In recent decades, scientists have conducted studies on the positive effects of nutrients available to different marine organisms on health, which may be the key to new treatments for diseases such as cancer, ${ }^{1}$ Alzheimer, ${ }^{2}$ human immunodeficiency virus $(\mathrm{VIH})^{3}$ or Parkinson. ${ }^{2}$ Food from the oceans is an excellent source of the macronutrients and micronutrients necessary for a healthy diet. In addition, it provides other valuable components such as docosahexaenoic acid (DHA) and eicosapentaenoic acid (EPA), both omega $3(\omega-3)$, important for optimal neurological development in children, ${ }^{4,5}$ for the improvement of cardiovascular health, ${ }^{6,7}$ diabetes $^{8}$ and epilepsy. ${ }^{9}$ Research has shown that fish consumption has health benefits in terms of reducing the risk of death from coronary heart disease and improving neurodevelopment in infants and young children when the mother consumes fish before and during pregnancy. ${ }^{10}$

The world production of fish oils reaches millions of tons, of which $88.5 \%$ is destined for aquaculture, and remains are destined to industrial production, human consumption and development of pharmaceutical products. ${ }^{11}$ According García Rodríguez ${ }^{12}$ the low levels of use of fish oil in human nutrition are mainly due to their characteristic odor and taste, as well as the high degree of unsaturation of their fatty acids that make them susceptible to oxidation, which has required the application of technological processes that improve their organoleptic properties and guarantee greater stability. These difficulties, together with the need to supplement human nutrition with oils of marine origin, have motivated the food industry to apply procedures that increase the nutritional intake of these fatty acids through the development of functional foods.

The deposit of fat in most cartilaginous fish is located mainly in the liver, some species such as shark and cod accumulate a considerable amount of oil in this organ. ${ }^{13}$ According to the literature it has been reported that the size and weight of the liver in sharks varies depending on the species and time of year and that in some sharks the liver can be up to $20 \%$ of the total weight of the animal. ${ }^{12,13}$ There are different methods for extracting oils from marine species that can be classified into three categories: physical, biological and chemical. ${ }^{14-17}$ Studies carried out express that the application of different extraction methods causes variation in the chemical properties of oils of marine origin. ${ }^{18,19}$ The physical methods of exraction are some of the most used, these include cooking/heating or processing, pressing, drying and grinding. The cooking step is designed to break the fat cells to release oil and press or centrifuge to separate the liquids from the dough. ${ }^{20-25}$ The cooking coagulates the protein, breaks down the fat deposits and releases oil and physicochemically bound water. The cooking step also prepares materials for subsequent operations in several processing units. The coagulation of fish protein occurs at approximately $75^{\circ} \mathrm{C}$, but cooking is typically in the temperature range of $95^{\circ} \mathrm{C}$ to $100^{\circ} \mathrm{C}$ for the duration of $(15$ to 20$)$ minutes. ${ }^{25}$ Direct and indirect cookers are also used. ${ }^{26}$ The extraction by heat is the most used, ${ }^{27}$ this physical agent favors the release of the oil from the liver cells, at the same time that it inactivates the lipolytic enzymes that 
cause the hydrolysis of the lipids (reaction that favors the oxidation of the fatty acids).$^{28}$ During the heating process, oxidative processes of the lipids can also be produced; the nature of these alterations depends on factors such as the temperature, the heating time, the degree of unsaturation of the oil, among others, ${ }^{29}$ therefore, new conditions for shark liver aeration are investigated, using the species Ginglimostoma cirratun, Carcharhinus longimanus, and Carcharhinus falciformis, captured in the north-central coast of Cuba.

\section{Materials and methods}

\section{Extraction of lipids}

Shark specimens of Ginglimostoma cirratun, Carcharhinus longimanus and Carcharhinus falciformis were captured in the Caribbean Sea near Villa Clara shore in Cuba in the summer (June) and winter (December) of 2018, respectively. Specimens, as well as their livers were weighed for hepatosomatic index (HSI). Dissected livers were placed in polyethylene bags and frozen at $-20^{\circ} \mathrm{C}$ for their transportation in coolers to the Empresa Pesquera Industrial de Caibarién (Villa Clara, Cuba). Livers were stored at $-80^{\circ} \mathrm{C}$, for no more than 2 weeks, until oil extraction. Livers were at thawed at room temperature and homogenized for 2 min using a 14-507-7 M cutter (Fisher Scientific, Pittsburgh, PA). The homogenized liver was heated at $50^{\circ} \mathrm{C}$ for $20 \mathrm{~min}$ and centrifuged at $7500 \mathrm{rpm}$ for $20 \mathrm{~min}$ at room temperature in a model TG16 Yingtai instrument centrifuge (Yingtai instrument Co., China), to release solid impurities from liver cells; then the oils were washed three times with hot distilled water $\left(50^{\circ} \mathrm{C}\right.$ $-60^{\circ} \mathrm{C}$ ); a second centrifugation was performed at 7500rpm in the oil that was released from the heavy fats and other impurities; these were clean and transparent with a characteristic light yellow color.

\section{Performance quantification}

It consisted of weighing $1 \mathrm{~kg}$ of sample (M); then the heavy portion was subjected to the extraction process, where the volume of oil obtained was quantified. Oil mass $(\mathrm{m})$ was determined by the relative density at $20^{\circ} \mathrm{C}$. The percent yield $(\% \mathrm{R})$ was calculated:

$$
\%_{R}=(\mathrm{m} / \mathrm{M}) * 100
$$

\section{Acidity value (AV) and percent free fatty acid (FFA)}

The AV and FFA was determined using the Brithis Pharmacopoeia ${ }^{30}$ method. Thirty millilitres of ether/ethanol/ water 3:3:2 (v/v/v) were used to dissolve $5 \mathrm{~g}$ of the sample and titrated against $0.1 \mathrm{~N}$ sodium hydroxide solution. ${ }^{31}$ FFA was expressed as percentage oleic acid. Acidity value $\left(\mathrm{W}_{\mathrm{AV}}\right)$ was calculated with the following formula:

$$
W_{A V}=\frac{56.1 * c * V}{m}
$$

Where: $\mathrm{V}$ is the volume of the standard volumetric solution of $\mathrm{KOH}$ in $\mathrm{mL}$; $\mathrm{c}$ is the exact concentration of the standard volumetric solution of $\mathrm{KOH}$ in mol. $\mathrm{L}^{-1} ; \mathrm{m}$ is the mass of the portion for analysis in grams.

Approximate content of FFA (acidity) was calculated by:

$$
W_{F F A}=0.5 * W_{A V}
$$

The acidity or the content of free fatty acid, $\mathrm{W}_{\mathrm{FFA}}$, expressed as a percentage of the mass fraction, and according to the type of fat (oleic acid), were obtained:

$$
W_{F F A}=\frac{V * c * M * 100}{1000 * m}
$$

Where: $\mathrm{V}$ is the volume of the standard volumetric solution of $\mathrm{KOH}$ in $\mathrm{mL}$; $\mathrm{c}$ is the exact concentration of the standard volumetric solution of $\mathrm{KOH}$ in mol. $\mathrm{L}^{-1}$; $\mathrm{M}$ is the molar mass of oleic acid in grams per mole $\left(282\right.$ g.mol $\left.{ }^{-1}\right) ; \mathrm{m}$ is the mass of the portion for analysis in grams.

\section{Refractive value (RV)}

The RI was determined by an Abbe refractometer at $20^{\circ} \mathrm{C}$ according to ISO method $6320 .{ }^{32}$

\section{Moisture content and volatile matters (MCVM)}

It was carried out in accordance with ISO 662: 2016. ${ }^{33}$ where three replications were made in each extraction. The moisture content and volatile matter $(\omega)$ expressed as percent mass is equal to:

$$
\omega=\left(\frac{m_{1}-m_{2}}{m_{1}-m_{0}}\right) * 100
$$

Where: $\mathrm{m}_{0}$ mass in grams of the bottle; $\mathrm{m}_{1}$ mass in grams of the bottle and the test portion before heating; $\mathrm{m}_{2}$ mass in grams of the bottle and the residue after heating.

\section{Percent conjugated diene (CD)}

CD was determined as per White. ${ }^{34}$ The sample $(90-130 \mathrm{mg})$ was added to $75 \mathrm{ml}$ of purified iso-octane in a $100 \mathrm{ml}$ flask. The flask was warmed to completely dissolve the sample, cooled to room temperature, allowed to stand for $15 \mathrm{~min}$, and then diluted to a final concentration of $0.01 / 1$. The absorbance was then measured at $233 \mathrm{~nm}$. Percentage $\mathrm{CD}$ was calculated as follows:

$$
C D=0.84\left[\frac{A_{S}}{b c}-K_{0}\right]
$$

Where $\mathrm{K}_{0}=$ absorptivity by acid or ester groups ( 0.07 for esters, 0.03 for acids), $\mathrm{A}_{\mathrm{s}}=$ observed absorbance at $233 \mathrm{~nm}, \mathrm{~b}=$ cuvette length in $\mathrm{cm}, \mathrm{c}=$ concentration of sample, $\mathrm{g} . \mathrm{L}^{-1}$ of the final dilution.

\section{Relative density (RD)}

The RD (specific weight) of the sample was determined through the method established by British Pharmacopoeia. ${ }^{35}$ It is calculated as shown below:

$$
\ddot{\mathrm{a}}=\frac{m_{1}-m_{0}}{m_{2}-m_{0}}
$$

Where: $\delta$ is the relative density of the oil, at the temperature in ${ }^{\circ} \mathrm{C}$ with respect to the water reference temperature; $\mathrm{m}_{1}$ is the mass in grams of the pycnometer with sample; $\mathrm{m}_{2}$ is the mass in grams of the pycnometer with water; $\mathrm{m}_{0}$ is the mass in grams of the empty pycnometer. The absolute density of the oil is obtained by multiplying the value obtained for the relative density by the absolute density of the water at $20^{\circ} \mathrm{C}(0.99823 \mathrm{~g} / \mathrm{mL}) .^{35}$

\section{Saponification value (SV)}

The procedure was carried out in triplicate, following the described in Brithis Pharmacopoeia. ${ }^{36}$ The oil was saponified by refluxing with a known excess of alcoholic $\mathrm{KOH}$ solution. The alkali required for saponification is determined by titration of the excess $\mathrm{KOH}$ with standard $\mathrm{HCl}$ solution $(0.5 \mathrm{M})$ and phenolphthalein. Saponification value was calculated with the following formula:

$$
I_{S}=\frac{\left(V_{0}-V_{1}\right) * c * 56.1}{m}
$$


Where: $\mathrm{V}_{0}$ is the volume in $\mathrm{mL}$ of the volumetric standard solution of $\mathrm{HCl}$ consumed in the blank assay; $\mathrm{V}_{1}$ is the volume in $\mathrm{mL}$ of the volumetric standard solution of $\mathrm{HCl}$ consumed in the sample assay; $\mathrm{c}$ is the concentration in moles per liter of the standard $\mathrm{HCl}$ solution; $\mathrm{m}$ is the mass in grams of the sample portion.

\section{Insoluble impurities in $\mathbf{n}$-hexane (II)}

The procedure was carried out as established in ISO 663: $2017 .^{37}$ The content of insoluble impurities (w) expressed as a percentage by mass is equal to:

$$
W=\left(\frac{m_{2}-m_{1}}{m_{0}}\right) * 100
$$

Where: $\mathrm{m}_{0}$ is the mass of the portion for analysis in grams; $\mathrm{m}_{1}$ is the mass of the vial together with its lid plus the filter paper; $m_{2}$ is the mass of the vial together with its lid plus the filter paper that contains the dry residue.

\section{P-anisidine value (p-AV)}

The $p$-AV was determined as per Bhattacharya et al, ${ }^{31}$ British Pharmacopoeia. ${ }^{38}$ The sample $(0.5-4.0 \mathrm{~g})$ was dissolved and diluted to volume with iso-octane in a $25 \mathrm{ml}$ volumetric flask. The absorbance $\mathrm{Ab})$ of the solution was measured at $350 \mathrm{~nm}$. Exactly $5 \mathrm{ml}$ of the fat solution were transferred to a test tube and $5 \mathrm{ml}$ of only the solvent were added to another test tube. One millilitre of $\mathrm{p}$-anisidine reagent $(2.5 \mathrm{~g} / 1$ solution in glacial acetic acid) was added to each tube, and shaken. After exactly $10 \mathrm{~min}$, the absorbance (As) of the solution in the first test tube was measured at $350 \mathrm{~nm}$, using the solution in the second test tube as blank. Anisidine value was calculated with the following formula:

$$
p-\mathrm{AV}=\frac{25 *\left[1.2 *\left(\mathrm{~A}_{\mathrm{S}}-\mathrm{A}_{\mathrm{b}}\right)\right]}{\mathrm{m}}
$$

As is absorbance of the fat solution after reaction with the $\mathrm{p}$-anisidine reagent, $\mathrm{Ab}$ is absorbance of the fat solution, $\mathrm{m}$ mass of the test portion in $\mathrm{g}$.

\section{Peroxide value (PV)}

The PV is the number that expresses in milliequivalents of active oxygen the quantity of peroxide contained in $1000 \mathrm{~g}$ of the substance, as determined by the method described below. PV was determined by titration with a $0.01 \mathrm{~N}$ sodium thiosulfate solution. ${ }^{39}$

The PV is expressed in milliequivalents of active oxygen per $\mathrm{kg}$.

$$
I P=\frac{V^{*} T * 1000}{m}
$$

Where $\mathrm{V}$ is the $\mathrm{mL}$ of the titrated solution of sodium thiosulfate used in the test, suitably corrected to take into account the blank test. $\mathrm{T}$ is the exact molarity of the sodium thiosulfate solution in mol. $\mathrm{L}^{-1}$ and $\mathrm{m}$ is the weight in grams of the problem sample.

\section{TOTOX value}

Totox was calculated with the following formula: $p$-anisidine value +2 peroxide value.

\section{Results}

The extracted oil was characterized taking into account parameters such as acidity value, percent free fatty acid, acidity expressed as \% oleic acid, refraction value, moisture content and volatile matters, percent conjugated diene, relative density, saponification value, insoluble impurities in n-hexane, anisidine value, peroxide value, TOTOX value.

The acidity index (Table 1) is considered as one of the main parameters that reflect the quality of the oil, the degree of refining, as well as the change of quality during storage; when an oil has a high acidity value, it points to the use of low quality raw material and poor handling or storage, so its consumption is not recommended. ${ }^{40}$ The sample taken from the shark liver pool was intentionally made on the exterior and interior of the sample, which resulted in the fact that the values of the acid index corresponding to the extractions (1 and 3) made on the outside were not comply with the limits established in Codex Alimentarius Commission ${ }^{41,45}$ ( $\leq 3 \mathrm{mg} \mathrm{KOH} / \mathrm{g}$ sample). This is due to poor handling or storage, ie the lack of adequate freezing or

\begin{tabular}{|c|c|c|c|c|c|c|c|c|c|c|c|c|}
\hline Extraction & AV & FFA* & FFA $* *$ & $\mathbf{R V}$ & CMMV & CD & RD & SV & II & AV & PV & TOTOX \\
\hline I & 3.3 & 0.46 & 0.46 & 1.469 & 0.29 & 2.24 & 0.91 & 171 & 0.3 & 9.3 & $\mathrm{I} .77$ & II.07 \\
\hline 2 & 0.76 & 0.38 & 0.38 & 1.468 & 0.15 & 1.99 & 0.91 & 153 & 0.99 & 8.9 & 2.66 & 11.56 \\
\hline 3 & 3.9 & 0.47 & 0.47 & 1.469 & 0.21 & 2.22 & 0.92 & 157 & 0.12 & 13.7 & 3.01 & 16.71 \\
\hline 4 & 0.75 & 0.38 & 0.38 & 1.468 & 0.14 & 1.99 & 0.91 & 171 & 0.22 & 14.9 & 3.05 & 17.95 \\
\hline 5 & 0.83 & 0.42 & 0.42 & 1.468 & 0.14 & $\mathrm{I} .83$ & 0.91 & 166 & 0.16 & 9.1 & 0.38 & 9.48 \\
\hline 6 & 0.78 & 0.39 & 0.39 & 1.469 & 0.16 & 2.11 & 0.91 & 156 & 0.73 & 13 & 4.17 & 17.17 \\
\hline 7 & 0.77 & 0.39 & 0.39 & 1.468 & 0.18 & $\mathrm{I} .88$ & 0.91 & 179 & 0.62 & 14.2 & 3.42 & 17.62 \\
\hline Average & 1.58 & $0.4 I$ & 0.41 & 1.468 & 0.18 & 2.04 & 0.91 & |64.7| & 0.44 & II.87 & 2.63 & I4. 14 \\
\hline
\end{tabular}
non-protection of the action of air and light; or to the aging of matter.

Table I Chemical properties of shark liver oil

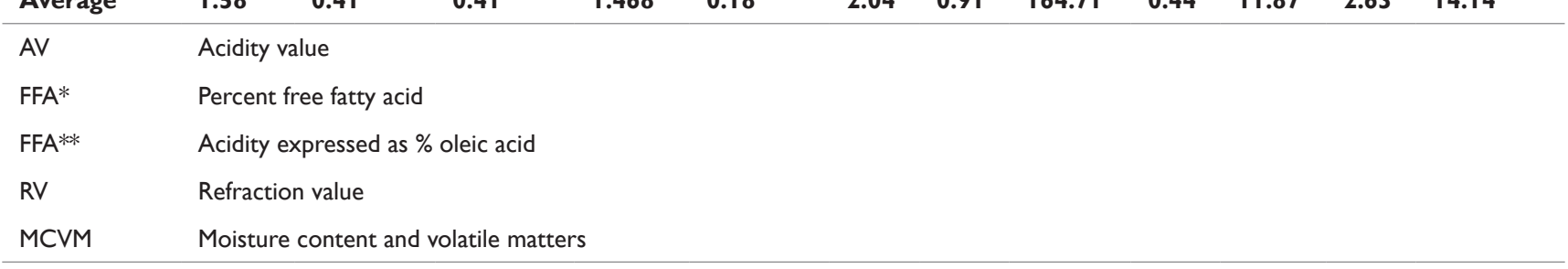




\begin{tabular}{|c|c|c|c|c|c|c|c|c|c|c|c|c|}
\hline Extraction & AV & FFA* & FFA** & $\mathbf{R V}$ & CMMV & CD & RD & is & II & AV & PV & тотох \\
\hline$C D$ & \multicolumn{12}{|c|}{ Percent conjugated diene } \\
\hline DR & \multicolumn{12}{|c|}{ Relative density } \\
\hline sV & \multicolumn{12}{|c|}{ Saponification value } \\
\hline II & \multicolumn{12}{|c|}{ Insoluble Impurities in n-hexane } \\
\hline p-AV & \multicolumn{12}{|c|}{ Anisidine value } \\
\hline PV & \multicolumn{12}{|c|}{ Peroxide value } \\
\hline тотох & \multicolumn{12}{|c|}{ Totox value } \\
\hline
\end{tabular}

However, the extractions 2, 4, 5, 6, and 7 comply with the quality values according to the previous standards, indicating that the enzymatic hydrolysis could be reduced due to an adequate conservation of the raw material, ${ }^{27}$ therefore, the oil obtained from the inside of the sample is kept in good condition. The research carried out by García Rodríguez ${ }^{12}$ express the acidity index in percent, according to the oleic acid $(0.9 \%)$, where the value is higher than the results obtained in the oil extracted from the interior of the shark liver pool. This figure is also adjusted to the maximum value established in the study of García et $\mathrm{al},{ }^{43}$ ( $\leq 1.5 \mathrm{mg} \mathrm{KOH} / \mathrm{g}$ sample). In comparison with the oil extracted from Clarias gariepinus whose acidity index was $2.8 \mathrm{mg} \mathrm{KOH} / \mathrm{g}$ sample, ours has a lower acidity as an average. ${ }^{44}$ The refractive index (Table 1) is also a property wid ely used to control the purity and quality of oils at both the laboratory and industrial levels. It is related to its average degree of establishment, and it is also useful to observe the progress of reactions such as hydrogenation and isomerization. The limits established for the refractive index according to García et $\mathrm{al}_{,}{ }^{43}$ (1.4557-1.4729), where the results obtained correspond to the described interval. The refractive index in oil and fats increases as the degree of unsaturation increases and the percentage of unsaturated acids increases, that is, increases proportionally to the length of the hydrocarbon chains and the number of double bonds in the chains. Therefore, the values reported in this study for the refractive index are a measure of the percentage of polyunsaturated fatty acids present in the oils analyzed.

The results achieved with respect to the relative density (Table 1) determined at $20^{\circ} \mathrm{C}$ in each extraction comply with the limits allowed according to García et al. ${ }^{43}$ However, it can not be said that the relative density obtained in each case complies with the provisions of Gupta et al. ${ }^{45}$ The study carried out by Paucar-Menacho et al, ${ }^{40}$ crude fish oil was used as raw material, where the relative density shows a higher value $(0.9308 \pm 0.0002)$ than those reported in this study. The saponification index (Table 1) gives a measure of the free and esterified fatty acids present in fats or oil. ${ }^{37}$ Fats or oils made up of long chain fatty acids have low values of saponification index because they have a relatively lower number of carboxylic functional groups per unit mass of fat or oil and, therefore, the molecular weight is high. ${ }^{47}$ The values obtained in this study are within the limits of the quality specification for the sample portion analyzed according to ISO 3657: $2013^{46}$ (150-200 $\mathrm{mg} \mathrm{KOH} / \mathrm{g}$ sample) and García et $\mathrm{al},{ }^{43}$ (129-215mg KOH/g sample). However, they are not included in the range expected by Gupta et $\mathrm{al}^{4}{ }^{45}$ (175-200), except for the extraction seven. The results exposed by Núñez-Gastélum ${ }^{48}$ for pigmented oils differ significantly from the results obtained for shark liver oil. As shown in Table 1, the resulting values in the analysis of insoluble impurities are less than $1 \%$, except extraction two, where it can not be said that it meets the maximum allowed value as it is proposed Gupta et al. ${ }^{45}$ This could be due to the undissolved fats still present in the oil, or to the poor handling of the procedure.

The peroxide index was used to estimate the primary oxidation of the oil and this is expressed as the milliequivalents of active oxygen present in $1000 \mathrm{~g}$ of oil or fat, and is the indicator that provides more information on the degree of oxidation of an oil or fat ${ }^{49}$ and measures the lipid peroxides, which are the main lipid oxidation products. ${ }^{39}$ As can be seen in Table 1, the results obtained for the extracted oil meet the limits established by Codex Alimentarius Commission ${ }^{42}(\leq 5$ meq oxygen/g sample), as well as within the quality specification limits for shark liver oil (2.69-6.84 meq oxygen/g sample). ${ }^{43}$ To evaluate the induction period of the oils, the anisidine index was used (Table 1 ), that increases rapidly when 2-alquenales are produced as a consequence of the initiation of the secondary oxidation of the fatty acids and the consequent rancidity. The results obtained in this study met the limit established by Codex Alimentarius Commission ${ }^{42}(\leq 20)$, therefore, as the compounds of aldehydes and dienes derived from secondary oxidation are within the limits of quality, we can affirm that the oil analyzed meets the requirements regarding this parameter.

According to Gupta et al, ${ }^{45}$ moisture content and volatile materials should not exceed $1 \%$ for shark liver oil. As reported in the table, the results corresponding to each oil extracted were less than $1 \%$, which is why the established indicator is met. In your study, García Rodríguez $\mathrm{z}^{12}$ affirms the good quality of the raw material used with a value of $1 \%$ humidity, which is higher than the ones obtained in this study. Therefore, the oils analyzed have low levels of moisture content and volatile materials, and an optimum quality. The total oxidation of the oil was determined through the relationship $2 \mathrm{PV}+\mathrm{AV}=\mathrm{TOTOX}$, according to Codex Alimentarius Commission, ${ }^{42}$ in which it is established that this value must be less than 30 , so that the extracted oil is mixed with the required oxidative quality concentrations.

The conjugated diene (CD) content of oils represents an early stage of oxidation (rancidity). The content of conjugated dienes was determined spectrophotometrically. The CD contents of shark liver oil were $2.04 \mu \mathrm{M}$. The value obtained is much lower than that reported by Navarro et al ${ }^{50}$ in his study of two ray (Rhinoptera bonasus and Aetobatus narinari) species from the Gulf of Mexico. The absorptions in the lengths indicated in the table reveal the presence of conjugated diene and trienic systems. $\mathrm{K}_{233}$ is a measure of primary oxidation related to the formation of hydroperoxides; in contrast, the measurement of absorbance at 270 and $280 \mathrm{~nm}$ is used for edible oils, where the absorption values are a measure of the secondary oxidation of the oil..$^{34}$ The visible ultraviolet spectrum $\left(\mathrm{K}_{233}=0.6759 \pm 0.0514\right.$; $\mathrm{K}_{270}=0.2762 \pm 0.031 ; \mathrm{K}_{280}=0.2446 \pm 0.0300$ ) corroborates that the pool of shark liver oil analyzed in this study is suitable for consumption. The percentage of conjugated dienes determined for this oil presents 
an average of 2.04, which shows that the oil extracted under these conditions has a good oxidative stability.

\section{Conclusion}

The extraction of the oil pool in the different liver samples of shark species captured in the north central coast of Cuba was carried out, applying a temperature of $50^{\circ} \mathrm{C}$ for 20 minutes, with a satisfactory yield of $58 \%$. The physicochemical characterization made to the oil pool, applying established tests or international standards, showed that it is suitable for consumption, as long as the sampling is carried out inside the sample because it is in better storage conditions.

\section{Acknowledgments}

None.

\section{Conflicts of interest}

Authors declare that there are no conflicts of interest.

\section{References}

1. Iagher F, de Brito Belo SR, Souza WM, et al. Antitumor and anticachectic effects of shark liver oil and fish oil: comparison between independent or associative chronic supplementation in Walker 256 tumor-bearing rats. Lipids Health Dis. 2013;12:146.

2. R Gopal, M Vijayakumaran, R Venkatesan, et al. Marine organisms in Indian medicine and their future prospects. Indian J Nat Prod Resour. 2008;7(2):139-145.

3. F Gunes. Medical use of squalene as a natural antioxidant. $J$ Marmara Univ Inst Heal Sci. 2013;3(4):220-228.

4. SS Al-Ghannami, Al-Adawi S, Ghebremeskel K, et al. Randomized open-label trial of docosahexaenoic acid-enriched fish oil and fish meal on cognitive and behavioral functioning in Omani children. Nutrition. 2019;57:167-172.

5. MS Coelho, SS Fernandes, M de las M. et al. Association Between Diet, Health, and the Presence of Bioactive Compounds in Foods. Bioactive Compounds. 2019;159-183.

6. JL Fidalgo, P Dynarowicz-Latka, J Miñones. Effects of saturated and polyunsaturated fatty acids on interactions with cholesterol versus 7-ketocholesterol in Langmuir monolayers and their potential biological implications. Colloids Surf B Biointerfaces. 2019;174:189-198.

7. MM Norde, E Oki, MM Rogero. C-Reactive Protein and Fatty Acids. The Molecular Nutrition of Fats. 2019;117-133.

8. T Behl, Madhuri Grover, Karan Shah, et al. Role of Omega-3-Fatty Acids in the Management of Diabetes and Associated Complications. Bioactive Food as Dietary Interventions for Diabetes. 2019;185-192.

9. S Tejada, M Martorell, X Capó, et al. Omega-3 Fatty Acids and Epilepsy. The Molecular Nutrition of Fats. 2019;261-270.

10. M DeCapo, JR Thompson, G Dunn, et al. Perinatal Nutrition and Programmed Risk for Neuropsychiatric Disorders: A Focus on Animal Models. Biol Psychiatry. 2019;85(2):122-134.

11. AGJ Tacon, M Metian. Global overview on the use of fish meal and fish oil in industrially compounded aquafeeds: Trends and future prospects. Aquaculture. 2008;285:1-4.

12. E García Rodríguez. Use of shark liver oil obtained in Cuba in the development of nutritionally improved products. 2005.

13. C Jayasinghe, $\mathrm{N}$ Gotoh, S Tokairin, et al. Inter species changes of lipid compositions in liver of shallow-water sharks from the Indian Ocean. Fish Sci. 2003;69(3):644-653.
14. P Nichols, M Rayner, J Stevens, et al. A Pilot Investigation of Northern Australian Shark Liver Oils: Characterization and Value-adding. Australia: FRDC Project Report 99/369, CSIRO Marine Research and Fisheries Research and Development Corporation; 2001.

15. M Kohlmeier. Fatty Acids. Nutrient Metabolism. 2015;111-186.

16. K Ivanovs, D Blumberga. Extraction of fish oil using green extraction methods: a short review. Energy Procedia. 2017;128:477-483.

17. C Wen, Zhang J, Zhang $\mathrm{H}$, et al. Advances in ultrasound assisted extraction of bioactive compounds from cash crops-A review. Ultrason Sonochem. 2018;48:538-549.

18. SS Nadar, P Rao, VK Rathod. Enzyme assisted extraction of biomolecules as an approach to novel extraction technology: A review. Food Res Int. 2018;108:309-330.

19. P Jayasinghe, I Adeoti, K Hawboldt. A Study of Process Optimization of Extraction of Oil from Fish Waste for Use as a Low-Grade Fuel. $J$ Am Oil Chem Soc. 2013;90(12):1903-1915.

20. Y Ozogul, A Simsek, E Ballkci, et al. The effects of extraction methods on the contents of fatty acids, especially EPA and DHA in marine lipids. Int J Food Sci Nutr. 2012;63(3):326-331.

21. D Fiorini et al. Comparison of Eleven Extraction Methods for Quantitative Evaluation of Total Lipids and Fatty Acids in the Clam Anadara inaequivalvis (Bruguière). J Shellfish Res. 2013;32(2):285290.

22. P Jayasinghe, K Hawboldt. A review of bio-oils from waste biomass: Focus on fish processing waste. Renew Sustain Energy Rev. 2012;16(1):798-821.

23. AG Tacon, MR Hasan, RP Subasinghe. Use of Fishery Resourse as Feed Inpouts to Aquaculture Development: Trends and Policy Implications. Rome: FAO Fisheries; 2006.

24. F Shahidi. Bailey's Industrial Oil and Fat Products. Hoboken, NJ, USA: John Wiley \& Sons Inc; 2005.

25. M Aursand, R Mozuraityte, K Hamre, et al. Description of the processes in the value chain and risk assessment of decomposition substances and oxidation products in fish Oils. Opinion of Steering Committee of the Norwegian Scientific Committee for Food Safety. 2011;

26. IA Adeoti, $\mathrm{K}$ Hawboldt. A review of lipid extraction from fish processing by-product for use as a biofuel. Biomass and Bioenergy. 2014;63:330-340.

27. I Aidos, A van der Padt, RM Boom, et al. Upgrading of Maatjes Herring Byproducts: Production of Crude Fish Oil. J Agric Food Chem. 2001;49(8):3697-704.

28. MD Guillén, A Ruiz, N Cabo. Study of the oxidative degradation of farmed salmon lipids by means of Fourier transform infrared spectroscopy. Influence of salting. J Sci Food Agric. 2004;84(12):15281534.

29. B Muik, B Lendl, A Molina-Díaz, et al. Direct monitoring of lipid oxidation in edible oils by Fourier transform Raman spectroscopy. Chem Phys Lipids. 2005;134(2):173-182.

30. British Pharmacopoeia. Acid Value. United Kingdom: Medicines and Healthcare products Regulatory Agency. 2013;2-9.

31. AB Bhattacharya, MG Sajilata, SR Tiwari, et al. Regeneration of thermally polymerized frying oils with adsorbents. Food Chem. 2008;110(3):562-570.

32. ISO. Animal and vegetable fats and oils-Determination of refractive index. Londres, United Kingdom: ISO/TC 34/SC 11 Animal and vegetable fats and oils; 2017. p. 6.

33. ISO. Animal and vegetable fats and oils-Determination of moisture and 
volatile matter content. United Kingdom: ISO/TC 34/SC 11 Animal and vegetable fats and oils; 2016. p. 1-7.

34. PJ White. Conjugated diene, anisidine value and carbonyl value analyses in Warner K and Eskin NAM. AOCS Press. 1995;159-178.

35. British Pharmacopoeia. Determination of Weight per Millilitre, Density, Relative Density and Apparent. United Kingdom: Medicines and Healthcare products Regulatory Agency; 2013:1-4.

36. British Pharmacopoeia. Saponification Value. United Kingdom: Medicines and Healthcare products Regulatory Agency; 2013. p. 9698.

37. ISO. Animal and vegetable fats and oils-Determination of insoluble impurities content. United Kingdom: ISO/TC 34/SC 11 Animal and vegetable fats and oils; 2017. p. 1-6.

38. British Pharmacopoeia. Anisidine Value. United Kingdom: Medicines and Healthcare products Regulatory Agency; 2013. p. 8-9.

39. G Yildiz, RL Wehling, SL Cuppett. Comparison of four analytical methods for the determination of peroxide value in oxidized soybean oils. J Am Oil Chem Soc. 2003;80(2):103-107.

40. LM Paucar Menacho, R Salvador Reyes, J Guillen Sanchez, et al Comparative study of physical-chemical features of sacha inchi oil (Plukenetia volubilis 1.), olive oil (Olea europaea) and fish oil. Sci Agropecu. 2015;279-290.

41. USP 35. Fish Oil. EE UU: United States Pharmacopeial; 2012. p. 5089.
42. FAO. Codex Alimentarius Commission. Rome, Italy: FAO; 2017;1-6.

43. CM García, M Fernández, M Castiñeira, et al. Evaluation and establishment of the quality specifications of the shark liver oil pool. Ars Pharm. 2014;55(1):23-29.

44. NC Ndidiamaka, OE Ifeanyi. Proximate and physicochemical analysis of oil obtained from two fish species (fresh and frozen). Int $J$ Adv Res Biol Sci. 2018;5:167-177.

45. P Gupta, K Singhal, AK Jangra, et al. Shark Liver Oil: A Review. Asian $J$ Pharm Educ Res. 2012;1(2):1-15.

46. ISO. Animal and vegetable fats and oils-Determination of saponification value. United Kingdom: ISO/TC 34/SC 11 Animal and vegetable fats and oils. 2013. p. 1-10.

47. M de los Angeles. Determination of the saponification index in corn oil using a lipase of national origin. Colombia: Universidad de los Andes; 2017.

48. JA Nunez-Gastelum et al. Physical-chemical evaluation of pigmented oil obtained from the shrimp head. Fats and Oils. 2011;62(3):321-327.

49. E Pereira, MC Ferreira, KA Sampaio, et al. Physical properties of Amazonian fats and oils and their blends. Food Chem. 2019;278:208215.

50. G Navarro García, JC Ramírez-Suárez, E Cota Quiñones, et al. Storage stability of liver oil from two ray (Rhinoptera bonasus and Aetobatus narinari) species from the Gulf of Mexico. Food Chem. 2010;119(4):1578-1583. 